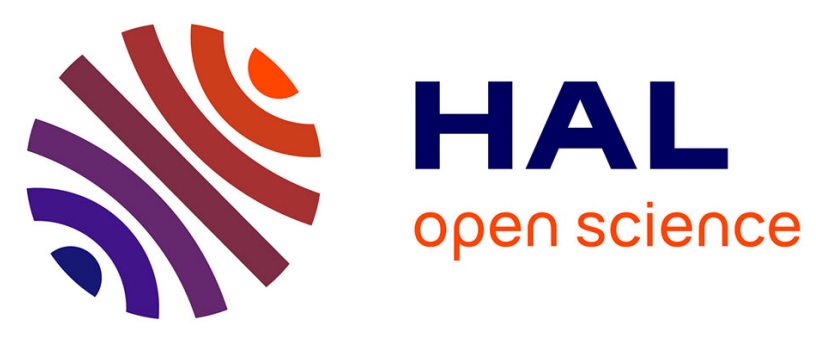

\title{
Occupational exposure to unintentionally emitted nanoscale particles and risk of cancer from lung to central nervous system - results from three French case-control studies
}

Guyguy Manangama, Céline Gramond, Sabyne Audignon-Durand, Isabelle Baldi, Pascale Fabro-Peray, Annabelle Gilg Soit Ilg, Pascal Guénel, Pierre Lebailly, Danièle Luce, Isabelle Stücker, et al.

\section{- To cite this version:}

Guyguy Manangama, Céline Gramond, Sabyne Audignon-Durand, Isabelle Baldi, Pascale FabroPeray, et al.. Occupational exposure to unintentionally emitted nanoscale particles and risk of cancer from lung to central nervous system - results from three French case-control studies. Environmental Research, 2020, 191, pp.110024. 10.1016/j.envres.2020.110024 . hal-02930142

HAL Id: hal-02930142

https://hal.science/hal-02930142

Submitted on 11 Sep 2020

HAL is a multi-disciplinary open access archive for the deposit and dissemination of scientific research documents, whether they are published or not. The documents may come from teaching and research institutions in France or abroad, or from public or private research centers.
L'archive ouverte pluridisciplinaire HAL, est destinée au dépôt et à la diffusion de documents scientifiques de niveau recherche, publiés ou non, émanant des établissements d'enseignement et de recherche français ou étrangers, des laboratoires publics ou privés. 


\section{Credit author statement}

Guyguy Manangama : Writing - Review \& Editing

Céline Gramond : Formal analysis, Writing - Review \& Editing

Sabyne Audignon-Durand : Resources, Writing - Review \& Editing

Isabelle Baldi : Resources, Writing - Review \& Editing

Pascale Fabro-Peray : Resources, Writing - Review \& Editing

Annabelle Gilg Soit Ilg : Resources, Writing - Review \& Editing

Pascal Guénel : Resources, Writing - Review \& Editing

Pierre Lebailly : Resources, Writing - Review \& Editing

Danièle Luce : Resources, Writing - Review \& Editing

Isabelle Stücker : Resources, Writing - Review \& Editing

Patrick Brochard : Conceptualization, Funding acquisition, Writing - Review \& Editing

Aude Lacourt : Conceptualization, Methodology, Supervision, Writing - Original Draft,

Writing - Review \& Editing 
1

\section{2}

Occupational exposure to unintentionally emitted nanoscale particles and risk of cancer: from

lung to central nervous system - results from three French case-control studies

3 Guyguy Manangama ${ }^{1}$, Céline Gramond ${ }^{1}$, Sabyne Audignon-Durand ${ }^{1}$, Isabelle Baldi ${ }^{1}$, Pascale Fabro-

4 Peray $^{2}$, Annabelle Gilg Soit $\mathrm{Ilg}^{3}$, Pascal Guénel ${ }^{4}$, Pierre Lebailly ${ }^{5}$, Danièle Luce ${ }^{6}$, Isabelle Stücker ${ }^{4}$,

5 Patrick Brochard ${ }^{1}$, Aude Lacourt ${ }^{1 *}$

$6{ }^{1}$ Univ. Bordeaux, Inserm, Bordeaux Population Health Research Center, Epicene team, UMR 1219,

$7 \quad$ F-33000 Bordeaux, France

$8 \quad{ }^{2}$ CHU Nîmes, BESPIM, F-30029 Nîmes, France

$9 \quad{ }^{3}$ Santé publique France, Direction Santé Travail, F-94415, Saint-Maurice cedex, France

${ }^{4}$ Centre de recherche en Epidémiologie et Santé des Populations (CESP), Cancer and Environment

team, Université Paris-Sud, Université Paris-Saclay, F-94800, Villejuif, France

${ }^{5}$ ANTICIPE, U1086 INSERM, Université de Caen Normandie, and Centre de Lutte Contre le Cancer

François Baclesse, F-14000 Caen, France

14

${ }^{6}$ Université de Rennes, Inserm, EHESP, Irset (Institut de Recherche en Santé, Environnement et

Travail) - UMR_S 1085, Pointe-à-Pitre, France

CORRESPONDING AUTHOR

17

Aude Lacourt

Tel: +33557571623

19

Fax: +33557574733

20

aude.lacourt@inserm.fr 
1

ABSTRACT

2 Objectives: Nanoscale particles $(1-100 \mathrm{~nm})$ can be of natural origin, and either intentionally or unintentionally produced by human activities. Toxicological data have suggested a possible carcinogenic effect of such particles. The aim of this study was to estimate the association between occupational exposure to nanoscale particles and risk of lung cancer, pleural mesothelioma and brain tumors in adults.

7 Methods: Three French population-based case-control studies were analyzed: 1) the ICARE study including 2,029 lung cancer cases and 2,591 controls; 2) the PNSM study including 371 pleural mesothelioma cases and 730 controls and 3) the CERENAT study including 257 brain tumor cases and 511 controls. Occupational exposure to unintentionally emitted nanoscale particles (UNPs) was retrospectively assessed by a job exposure matrix providing a probability and a frequency of exposure.

Results: In adjusted analyses among men, significant associations between occupational exposure to UNPs and lung cancer (OR=1.51; 95\% CI: $1.22-1.86$ and brain tumors $(\mathrm{OR}=1.69 ; 95 \% \mathrm{CI}: 1.17-2.44)$ were observed. No increased OR was observed for pleural mesothelioma $(\mathrm{OR}=0.78 ; 95 \% \mathrm{CI}$ : $0.46-$ $1.33)$.

Conclusion: This is the first study showing positive associations between occupational exposure to UNPs and increased risk of lung cancer and brain tumors. These preliminary results should encourage further epidemiological research. nanoscale particles.

Keywords: cancer; lung; central nervous system; occupational exposure; unintentionally emitted 
1

2

3 Funding sources: INCA - grant number SHSESP11-061

4

5 
1. Introduction

2 Particulate matter (mainly $\mathrm{PM}_{2.5}$ ) in outdoor air pollution has been classified by IARC (the International Agency for Research on Cancer) as carcinogenic to humans, with sufficient evidence for lung cancer (Loomis et al., 2014). The composition of particulate matter aerosol is complex in terms of particle size range and chemical composition and it is still unclear whether the observed adverse human's health effect should be attributed to a specific particle size range (Stone et al., 2017; Wichmann et al., 2000).

Among more complex definition, nanoscale particles (NPs) may be defined as particles with at least one dimension in the size range $1 \mathrm{~nm}-100 \mathrm{~nm}$. They may be naturally occurring (from volcano ashes, wild fires), unintentionally produced from anthropogenic processes (combustions, welding, diesel engine exhaust) or intentionally produced for commercial purposes due to their physico-chemical properties (medicine, automobile industry, cosmetic industry, food processing industry, etc.) (Oberdorster et al., 2005).

Regarding their potential adverse health effects, NPs have demonstrated a higher toxicity and an increased biological reactivity compared to micron-sized particles of identical chemical composition and for an equivalent mass concentration (Stone et al., 2017). In terms of cancer endpoints, the toxicological mechanisms described have led to the hypothesis of a potential association between exposure to NPs and cancer occurrence (Donaldson and Poland, 2012). Indeed, once inhaled into the lungs, NPs trigger an inflammatory response within the lung but also a systematic response through the release of inflammatory mediators into the blood stream (Oberdorster et al., 2005). Besides inflammation, genotoxic effects have been documented following exposure to NPs, either directly through direct interaction with DNA or mitotic spindle apparatus or indirectly through oxidative damages (Donaldson et al., 2010b; Magaye et al., 2012; Magdolenova et al., 2014; Moller et al., 2014; Toyokuni, 2013). From carcinogenicity studies, the lung cancer hypothesis as well as the mesothelioma hypothesis have been put forward, especially those linked to multiwalled carbon nanotubes (Ju et al., 2017; Suzui et al., 2016). Finally, NPs may also translocate from the lungs to 
different organs, including the brain, due to their capability to cross biological barriers, for instance the

2 alveolar capillary barrier, placental barrier and the blood-brain barrier (Campagnolo et al., 2017; Elder

3 and Oberdorster, 2006; Nakane, 2012; Nemmar et al., 2001; Oberdorster et al., 2005, 2002).

4 Additionally, NPs may also reach the brain through the olfactive nerve (Oberdorster et al., 2009).

While epidemiological evidence of the carcinogenicity of NPs has been derived from particulate matter in outdoor air pollution studies (Beelen et al., 2014; Goldberg et al., 2017; Ostro et al., 2015; Weichenthal et al., 2020, 2017a, 2017b) or diesel exhaust engine emission studies (classified by IARC as carcinogenic to humans due to sufficient evidence for lung cancer), little is known regarding occupational exposures to nanoscale particles. Liou et al reviewed the first epidemiological studies related to nanomaterials and concluded that there was a lack of consistency between studies; nonetheless, the results suggested that occupational exposure to nanomaterials may have detrimental effects on human health (Liou et al., 2015). Same conclusions were drawn by Schulte et al in 2019 (Schulte et al., 2019).

In addition, in the occupational setting, workers may be exposed to unintentionally emitted nanoscale particles in high concentrations, as compared to particulate matter exposure from outdoor air pollution among the general population, possibly conferring a high risk of cancer to certain occupational groups. We thus undertook the present analysis to assess the association between occupational exposure to unintentionally emitted nanoscale particles (UNPs) and cancer occurrence, and more specifically lung cancer, pleural mesothelioma and brain tumors.

\section{Methods}

\subsection{Study populations}

We analyzed three datasets from three population-based case-control studies which aimed at identifying environmental risk factors for lung cancer, pleural mesothelioma and brain tumors.

The lung cancer study (ICARE) was conducted between 2001 and 2007 in 10 French 'departments' (administrative areas) and has been described in detail previously (Luce et al., 2011). In total, 2926 
incident cases of histologically confirmed lung cancer (C33-C34 ICD-O) in consenting patients aged

218 to 75 years were included in the study. Controls, frequency-matched to cases by sex, age $(<40$ years, 40-54, 55-64,>65 years) and 'departments' of residence, were selected by list-assisted random digit dialing according to the incidence density sampling method.

The pleural mesothelioma study (PNSM), also previously described in detail (Rolland et al., 2010), included patients with incident pleural mesothelioma, following a standardized procedure for pathological and clinical confirmation of the diagnosis, between 1998 and 2002 in 19 'departments' of France. Two population controls were randomly selected from electoral lists and matched to each case for sex, age (+/- 5 years) and 'department' of residence.

Finally, the brain tumor study (CERENAT), previously described by Coureau et al. (Coureau et al., 2014), was conducted between 2004 and 2006 in four French 'departments'. Patients diagnosed with an incident benign or malignant CNS tumor were exhaustively identified from population-based cancer registries. Histological types were grouped into categories: gliomas, meningiomas, lymphomas and other unspecified primary brain tumors. For each case, two controls were randomly selected from the general population based on the electoral lists. Cases and controls were individually matched on age (+/- 2 years), sex and department of residence.

\subsection{Data collection}

Socio-demographic characteristics, residential history, personal and familial history of cancer, and detailed occupational history were collected in the three studies. Lifestyle characteristics (including detailed smoking history, alcohol consumption) were collected in the ICARE and CERENAT studies but not in the PNSM. Each study collected additional specific information related to the particular objectives of each study.

In all studies, lifetime occupational history was collected, including each job held for at least 6 months (one month for the ICARE study). As a minimum, the following information was recorded: job title, industrial branch, start year and end year, and description of main tasks. 


\subsection{Exposure assessment}

Lifetime occupational exposure to UNPs was retrospectively assessed using a specific job exposure matrix (JEM) for unintentionally emitted nanoscale particles, the MatPUF JEM, developed by industrial hygienists between 2010 and 2014. Each step in the construction of this JEM, described below, was validated by a multidisciplinary panel of 23 experts from various disciplines ( 3 aerosol metrologists, 3 chemists, 7 industrial hygienists or risk assessment specialists, 8 occupational physicians and, or both toxicologists and 2 epidemiologists) who together had the necessary specific knowledge to understand UFP exposure assessments. In this JEM, UNPs were defined as 1-100 nm solid particles, unintentionally produced by human activities at work (Audignon-Durand S, Gramond C, Ducamp S, Manangama G, Garrigou A, Delva F, Brochard P, Lacourt A. Annals of work exposures and health. under review)."

Through an extensive literature review (more than 300 published articles dealing with metrological data, See supplementary table 1 for more details), sources of emissions at the workplace of UNPs were identified. These emission sources were linked to work processes that may have an impact on materials commonly worked with and which may lead to the emission of NPs. These work processes involved high temperatures, combustion, and mechanical processes with high energies. Overall, 57 work processes grouped into 9 major categories were considered as emitting UNPs (See supplementary table 2 for details).

For each work process, the chemical families of UNPs were categorized into 7 classes: 1-Metallic particles; 2- Mineral particles; 3-Carbon particles; 4-Polycyclic Aromatic Hydrocarbon (PAH) particles; 5-Polymer particles, mainly plastics; 6-Wood particles; 7-Other organic particles.

For each occupational code in the international standard classification of occupations, edition 1968 (ISCO-68), the industrial hygienists determined whether they involved at least one of the 57 previously defined work processes. Exposure parameters in terms of probability and frequency of exposure were then assessed for each combination of an occupation and a work process: 
1 - The probability of exposure was defined as the proportion of workers who might be exposed to

2 UNPs through the implementation of the work process among workers involved in that occupation.

3 The probability of exposure was defined on a semi-quantitative scale and numerical values

4 corresponding to the class center were assigned to each class (Table1).

- The frequency of exposure was defined as the proportion of working time during which the exposure occurred through the implementation of the work process in a typical 8-hr working day and in a typical working year. The frequency of exposure was defined on a semi-quantitative scale and numerical values corresponding to the class center were assigned (Table 1).

Due to the heterogeneity of quantitative data in terms of measurement protocols as well as concentration units (mass concentration, number concentration, surface area concentration) and the lack of quantitative data for a large number of work processes at the time the JEM was built, the experts were unable to assess the 'intensity of exposure' parameter.

Finally, the probability and frequency of exposure were computed at the occupation level by summarizing the exposure parameters assessed at the occupational code-work processes level (Table 1). For some specific occupational code/work process combinations, the industrial branch (based on the activities of the French classification NAF edition 2000), was considered in the exposure assessment.

\subsection{Potential confounders}

For lung cancer, smoking, occupational asbestos exposure and occupational silica exposure were considered as potential confounders. Lifetime smoking history was assessed by the comprehensive smoking index (CSI) (Leffondre et al., 2006). Lifetime occupational exposures to asbestos and to silica in the ICARE study were assessed by two specific job-exposure matrices and summarized through cumulative exposure indices (Guida et al., 2013). 
1 For pleural mesothelioma, only lifetime occupational asbestos exposure was considered as a potential

2 confounder. It was retrospectively assessed by experts and summarized though a cumulative index of

3 exposure (Lacourt et al., 2017).

4 Finally, for CNS tumors, lifelong pesticide exposure as well as cumulative duration of mobile phone 5 calls were considered.

\subsection{Statistical analysis}

\subsubsection{Main analysis}

Subjects were defined as "probably exposed" to UNPs if they had held at least one job with a probability of exposure of at least $50 \%$. Subjects who had held jobs with a probability of exposure less than $50 \%$ but greater than $0 \%$ were considered to be "possibly exposed" to UNPs.

For each exposed subject, we derived the total duration of exposure in years and the total weighted duration of exposure, which was the sum of durations of exposure for each job held by a subject weighted by the frequency of exposure. For subjects who had held more than one job over the same year, we counted 6 months for each job in the calculation of the duration of exposure.

Odds ratios of lung cancer associated with UNPs were estimated using unconditional logistic regression adjusted for age (using fractional polynomial of degree 2 with powers $\mathrm{p}=-2$ and $\mathrm{q}=-2$ ), department of residence, comprehensive smoking index (CSI), the cumulative index of exposure to asbestos (using fractional polynomial of degree 1 with powers $\mathrm{p}=-1$ ) and the cumulative index of exposure to silica (using fractional polynomial of degree 1 with powers $\mathrm{p}=-1$ ).

Associations between UNPs and pleural mesothelioma or CNS tumors were estimated using conditional logistic regression stratified by age (5-year categories) and district of residence and further adjusted for age as a continuous variable (in order to remove any residual confounding due to age in the strata definition). For pleural mesothelioma, models were further adjusted for the cumulative index of exposure to asbestos (using fractional polynomial of degree 2 with powers $p=-2$ and $q=0.5$ ). For 
1 CNS tumors, analyses were carried for all histological types and for neuroepithelial tumors and

2 meningiomas separately.

3 Analyses were conducted on men and women separately.

\subsubsection{Sensitivity analyses}

In addition, sensitivity analyses were performed for CNS tumors by adjusting for pesticide exposure (binary variable) and the cumulative duration of calls (hours) categorized into light-medium or heavy users.

3. Results

Some characteristics of cases and controls included in the three studies are presented in supplementary file (Supplementary tables 3 and 4) and have been described in detail elsewhere (Coureau et al., 2014; Luce et al., 2011; Rolland et al., 2010).

Table 2 presents the 20 most frequent occupations held by subjects in the three studies ( 36 occupations in total) which have led to occupational exposure to UNPs (corresponding to the "probable exposure" criterion). For the ICARE study, lorry and van driver occupations were held by $9.7 \%$ of cases and $8.2 \%$ of controls and were considered as occupationally exposed to carbonaceous and PAH UNPs through the combustion engine process. In the PNSM study, sheet-metal workers accounted for $8.1 \%$ of cases and $2.1 \%$ of controls and entailed occupational exposure to metallic and carbonaceous UNPs through the machining, welding and thermal cutting processes. Finally, in the CERENAT study, the most frequently exposed occupations were farmers, who accounted for $11.3 \%$ of cases and $9.2 \%$ of controls.

Table 3 presents the adjusted associations between UNPs and lung cancer or pleural mesothelioma among men. When comparing probably exposed subjects with never exposed subjects, the OR was 1.51 (95\% CI: 1.22-1.86) for lung cancer. When considering the probability of exposure, the OR was 1.59 (95\%CI: $1.25-2.02)$ for subjects exposed with a probability of exposure between $50 \%$ to $90 \%$ and 
1.46 (95\% CI: $1.17-1.83$ ) for subjects exposed with a probability greater than $90 \%$ compared to nonexposed. When restricting the analyses to probably exposed subjects, the OR associated with a oneyear increase in the total weighted duration of exposure was 1.09 (95\% CI: 0.99-1.20) and 1.06 (95\% CI: 0.99-1.13) for the duration of exposure (unweighted by frequency). For pleural mesothelioma, the adjusted OR was 0.78 (95\% CI: 0.46-1.33) for subjects probably exposed to UNPs compared to non-exposed subjects.

Table 4 presents the adjusted associations between UNPs and CNS tumors among men, overall and for neuroepithelial tumors and meningiomas separately. Considering all CNS tumors, the OR comparing probably exposed subjects to non-exposed subjects was significantly increased $(\mathrm{OR}=1.69 ; 95 \% \mathrm{CI}$ : 1.17-2.44) and ORs tended to be greater for meningiomas than for neuroepithelial tumors $(\mathrm{OR}=2.19$; 95\% CI: $0.96-5.01$ and $\mathrm{OR}=1.47$; $95 \% \mathrm{CI}: 0.91-2.36$, respectively for probably exposed $v s$ nonexposed subjects). There was no clear trend for either the probability of exposure or the total weighted duration of exposure or the unweighted duration among exposed subjects.

Finally, Table 5 presents adjusted associations between UNP chemical families and lung cancer in men. It was unclear whether the magnitude of the ORs was associated with a specific chemical family or a mixture of chemical families. For example, the OR comparing subjects exposed concomitantly to metallic, mineral, carbonaceous and wood UNPs to non-exposed subjects was 1.40 (95\% CI: 1.03 1.90), but it was also of the same magnitude for subjects exposed only to carbon UNPs $(\mathrm{OR}=1.41$; 95\% CI: $1.06-1.87)$ or only to wood UNPs (OR=1.44; $95 \%$ CI: $0.74-2.81)$. It was impossible to perform such analyses for pleural mesothelioma and CNS tumors due to the small sample sizes.

No significant associations were observed among exposed women $(\mathrm{OR}=1.07 ; 95 \%$ 0.79-1.46 for the ICARE study; OR=1.89; 95\% CI: $0.93-3.85$ for PNSM study and OR=0.78; 95\% CI: $0.54-1.13$ for the CERENAT study) (See supplementary material tables 5 and 6).

For CNS, although we thought a priori that pesticide and mobile phone exposures were not confounding factors in the relationship between UNPs and CNS tumors, we performed a set of 
sensitivity analyses by adjusting for those two factors. Estimated ORs was similar to those presented in the main analyses (Supplementary table 7).

\section{Discussion}

Our results reveal a positive association between occupational exposure to UNPs and lung cancer and CNS tumors, while this association was not observed for pleural mesothelioma. For lung cancer, all analyses were adjusted for the main potential confounders (smoking, asbestos and silica exposure). For smoking, we used the comprehensive smoking index which has been shown to perform well in adjusting for smoking in lung cancer studies (Leffondre et al., 2006). Given that occupational exposure to asbestos is strongly associated with pleural mesothelioma and ORs are close to the null regarding the relationship between UNPs and pleural mesothelioma, with the inclusion of asbestos exposure data in the analyses as a confounding factor, it is unlikely that the ORs observed for lung cancer are due to residual confounding from asbestos exposure. However, we were not able to consider exposure to PM2.5 from outdoor air pollution, a well-established lung carcinogen (IARC group 1), since PM2.5 exposure monitoring was implemented in France since 2010 only. Although confounding from outdoor air pollution is not likely to explain the whole association between occupational exposure to nanoscale particles and lung cancer, we acknowledge that this is a limitation of our study.

For CNS tumors, except for ionizing radiation, which is a well-established risk factor, the etiology of these tumors is largely unknown, with some environmental exposures being investigated such as mobile phone use or pesticide exposure (McNeill, 2016). Since the sensitivity analyses that we performed by further adjusting for mobile phone use or pesticide exposure did not significantly change the estimated ORs, we thus believe that the likelihood that our results were confounded by a third factor is low.

Clinical controlled exposure (mainly to $\mathrm{PM}_{2.5}$ or diesel exhaust particles) studies have demonstrated airway inflammation in healthy subjects (Ghio et al., 2012; Xu et al., 2017), exacerbation of preexisting conditions such as asthma (McCreanor et al., 2007; Patel et al., 2013) and respiratory and 
cardiovascular responses to traffic-related aerosol (Sinharay et al., 2018) Furthermore, exposure to

2 ultrafine particles from ambient air pollution is associated with numerous pre-clinical or clinical

3 cardiovascular endpoints (Bourdrel et al., 2017; Weichenthal, 2012).

4 The brain hypothesis has been put forward following observation of neurological impairment

5 following exposure to PM in highly polluted Mexico cities (Calderon-Garciduenas et al., 2016).

6 Following that, numerous studies have implicated NPs in the development of several neurological

7 disorders such as Parkinson's disease, Alzheimer's disease and sclerosis, as well as behavioral

8 changes and cognitive developments (Heusinkveld et al., 2016). Indeed, UNPs may translocate into

9 the brain through the brain-blood barrier passage following inhalation, deposition and translocation into the bloodstream or via the olfactory nerves (Oberdorster et al., 2009). In vivo studies have demonstrated that nanoscale particle exposure is associated with indicators of neural inflammation, either directly from particles which enter into the brain or through the systemic inflammation generated (Campbell et al., 2005; Hopkins et al., 2018).

Due to their small size, UNPs may penetrate deep into the lungs (Oberdorster et al., 2005). Moreover, their small size prevents macrophages from effectively taking them up, which generate oxidative stress and inflammatory responses (Val et al., 2009). Finally, UNPs may translocate outside the lungs and enter into the blood stream and thus accumulate in secondary organs (Stone et al., 2017).

Regarding epidemiological data, most knowledge related to UNPs is derived from ambient air pollution studies. While UNPs do not contribute to the mass concentration of particulate matter exposure to the same extent as coarse particles, UNPs are predominant in terms of particle numbers and have been incriminated in the observed adverse health effects (Delfino et al., 2005). Despite rather inconclusive results from previous studies regarding lung cancer and exposure to nanoscale particles from outdoor air pollution (Ostro et al., 2015; Weichenthal et al., 2017a), Weichenthal et al, have recently showed a positive association between nanoscale particles from outdoor air pollution and brain tumors which was not explained by other air pollutants such as PM2.5 mass concentrations 
1 Regarding the occupational setting, a recent literature review has identified all occupational cohorts

2 related to engineered nanomaterials workers. While this review has reinforced the UNPs hypothesis,

3 with most studies demonstrating short-term effects such as a reduction in pulmonary function or

4 inflammatory responses, it has also pointed out the limited epidemiological data and the need for

5 longitudinal epidemiological studies (Schulte et al., 2019) as others (Ohlwein et al., 2019). UNPs aerosol composition is complex, in terms of both chemical composition and particle size distribution. Despite the difference between UNPs aerosols and nanomaterial aerosols, they share numerous physicochemical and toxicological properties, which may be used to extrapolate results from one exposure to the other (Stone et al., 2017).

The main challenge regarding UNPs exposure is related to retrospective exposure assessment. In this study, we used a JEM to retrospectively assess occupational exposure to UNPs. Such methods prevent recall bias regarding exposure if cases do not recall their occupational career as accurately as controls. Previous studies have shown a good validity of self-reported work history without systematic errors between cases and controls (Schlaefer et al., 2009; Teschke et al., 2002).

Besides the limitations of the job-exposure matrix in general, the MatPUF JEM only provides a probability and a frequency of exposure parameters. Indeed, at the time of construction of the MatPUF JEM, it was impossible to a priori estimate an intensity of exposure parameter from the available metrological data due to the heterogeneity of published data in terms of measurement methods as well as the units used to express UNPs concentration (mass concentration vs particulate number vs surface area) (Brouwer et al., 2012). Without an intensity of exposure parameter, it is impossible to estimate dose-response relationships. We tried to approximate this parameter by analyzing the total weighted duration of exposure. Most results were inconclusive with ORs being around the null. Analyses with the duration of exposure (unweighted by frequency) showed similar results. Since UNPs exposure is ubiquitous at the workplace, it is highly probable that the longest duration of exposure categories may include subjects with high intensity of exposure as well as those with low or very low intensity of exposure, leading to ORs close to 1 . To overcome this main limitation, we are currently working on a new version of the MatPUF JEM that will integrate the intensity of exposure parameter. 
1 In analyses conducted in women, we did not find significant associations in the three studies. This

2 could be explained on the one hand by the low number of cases among women and on the other hand

3 by the method used to characterize the exposure. The use of JEM in female populations shows

4 limitations related to their sensitivity that may lead to underestimations of association measures. It has

5 been shown that women and men with the same job title do not perform the same tasks. Women are expected to have lower occupational exposure than men with the same job title (Bertin et al., 2018; Messing et al., 1994).

Regarding the results for pleural mesothelioma, in accordance with the hypotheses discussed by Donaldson (Donaldson et al., 2013) for the toxicity of elongated insoluble fine particles, the absence of excess risk (in relation to non-elongated nanoscale particles) is not very surprising. Indeed, he describes how only carbon nanotubes that are sufficiently long and bio persistent may translocate to the pleura, where they can be retained and cause inflammation and oxidative stress. In the overall occupational situation described in the JEM, the probability of being exposed to elongated carbon nanotubes during the job histories of participants in our study is negligible. In addition, regarding exposure to asbestos, which is an elongated particle, an adjustment has been made to take this confounding factor into account. Given that the relationship between asbestos exposure and pleural mesothelioma is much stronger among men, it is unlikely that our analyses might be confounded by a third factor.

The three studies analyzed were population-based case-control studies which included incident cases during the study recruitment period and randomly selected controls from the general population (Coureau et al., 2014; Luce et al., 2011; Rolland et al., 2010). Analyzing already-constituted casecontrol studies which have gathered the entire occupational history of subjects might be a way to obtain additional knowledge on the association between occupational exposure to nanoscale particles and cancer.

In total, despite the use of the JEM, which could lead to a classification error and thus to an underestimation of associations, we were able to confirm the existing hypothesis of an over-risk of 
1 lung cancer associated with work situations exposing subjects to specific ultrafine particles (such as

2 diesel exhaust and welding fumes) (Loomis et al., 2014). Indeed, our data are consistent with the

3 probable contribution of the whole spectra of ultrafine particles to lung cancer risk. We were also able

4 to confirm the biologically plausible association between particle exposure and brain tumors, based on

5 toxicological data (Oberdorster et al., 2009). Finally, our study allowed us to rule out an association

6 between exposure to UNPs and pleural mesothelioma, which, based on toxicological data describing

7 the translocation mechanisms of non-elongated particles, appears less plausible (Donaldson et al., 8 2010a).

\section{Conclusion}

To the best of our knowledge, this is the first study to show positive associations between occupational exposure to UNPs and increased risk of lung cancer and CNS tumors. A large number of people are potentially exposed to the UNPs, so their impact in terms of public health may not be negligible. Even though these preliminary results should be confirmed by other analyses including intensity of exposure, these results should encourage further epidemiological research on nanoscale particles and cancer.

\section{Competing financial interests declaration}

All authors declare they have no actual or potential competing financial interest.

\section{Contributors}

AL performed the literature review, planned the statistical analysis, and drafted the first version of this manuscript

GM performed the literature review and wrote the final version of the manuscript, taking into account the inputs of each co-author 
CG performed all statistical analyses presented in the manuscript

SA performed the literature review on exposure data and built the job-exposure matrix PB supervised

all aspects of this manuscript

All co-authors participated in the editing and correction of the final text

\section{REFERENCES}

Beelen, R., Raaschou-Nielsen, O., Stafoggia, M., Andersen, Z.J., Weinmayr, G., Hoffmann, B., Wolf, K., Samoli, E., Fischer, P., Nieuwenhuijsen, M., Vineis, P., Xun, W.W., Katsouyanni, K., Dimakopoulou, K., Oudin, A., Forsberg, B., Modig, L., Havulinna, A.S., Lanki, T., Turunen, A., Oftedal, B., Nystad, W., Nafstad, P., De Faire, U., Pedersen, N.L., Ostenson, C.G., Fratiglioni, L., Penell, J., Korek, M., Pershagen, G., Eriksen, K.T., Overvad, K., Ellermann, T., Eeftens, M., Peeters, P.H., Meliefste, K., Wang, M., Bueno-de-Mesquita, B., Sugiri, D., Kramer, U., Heinrich, J., de Hoogh, K., Key, T., Peters, A., Hampel, R., Concin, H., Nagel, G., Ineichen, A., Schaffner, E., Probst-Hensch, N., Kunzli, N., Schindler, C., Schikowski, T., Adam, M., Phuleria, H., Vilier, A., Clavel-Chapelon, F., Declercq, C., Grioni, S., Krogh, V., Tsai, M.Y., Ricceri, F., Sacerdote, C., Galassi, C., Migliore, E., Ranzi, A., Cesaroni, G., Badaloni, C., Forastiere, F., Tamayo, I., Amiano, P., Dorronsoro, M., Katsoulis, M., Trichopoulou, A., Brunekreef, B., Hoek, G., 2014. Effects of long-term exposure to air pollution on natural-cause mortality: an analysis of 22 European cohorts within the multicentre ESCAPE project. Lancet 383, 785-95.

Bertin, M., Thebaud-Mony, A., Counil, E., Giscop93 study, group, 2018. Do Women and Men Have the Same Patterns of Multiple Occupational Carcinogenic Exposures? Results from a Cohort of Cancer Patients. Ann Work Expo Health 62, 450-464.

Bourdrel, T., Bind, M.A., Bejot, Y., Morel, O., Argacha, J.F., 2017. Cardiovascular effects of air pollution. Arch Cardiovasc Dis 110, 634-642.

Brouwer, D., Berges, M., Virji, M.A., Fransman, W., Bello, D., Hodson, L., Gabriel, S., Tielemans, E., 2012. Harmonization of measurement strategies for exposure to manufactured nano-objects; report of a workshop. Ann Occup Hyg 56, 1-9.

Calderon-Garciduenas, L., Leray, E., Heydarpour, P., Torres-Jardon, R., Reis, J., 2016. Air pollution, a rising environmental risk factor for cognition, neuroinflammation and neurodegeneration: The clinical impact on children and beyond. Rev Neurol (Paris) 172, 69-80.

Campagnolo, L., Massimiani, M., Vecchione, L., Piccirilli, D., Toschi, N., Magrini, A., Bonanno, E., Scimeca, M., Castagnozzi, L., Buonanno, G., Stabile, L., Cubadda, F., Aureli, F., Fokkens, P.H., Kreyling, W.G., Cassee, F.R., Pietroiusti, A., 2017. Silver nanoparticles inhaled during pregnancy reach and affect the placenta and the foetus. Nanotoxicology 11, 687-698.

Campbell, A., Oldham, M., Becaria, A., Bondy, S.C., Meacher, D., Sioutas, C., Misra, C., Mendez, L.B., Kleinman, M., 2005. Particulate matter in polluted air may increase biomarkers of inflammation in mouse brain. Neurotoxicology 26, 133-40. 
Coureau, G., Bouvier, G., Lebailly, P., Fabbro-Peray, P., Gruber, A., Leffondre, K., Guillamo, J.S., Loiseau, H., Mathoulin-Pelissier, S., Salamon, R., Baldi, I., 2014. Mobile phone use and brain tumours in the CERENAT case-control study. Occup Environ Med 71, 514-22.

Delfino, R.J., Sioutas, C., Malik, S., 2005. Potential role of ultrafine particles in associations between airborne particle mass and cardiovascular health. Environ Health Perspect 113, 934-46.

Donaldson, K., Murphy, F.A., Duffin, R., Poland, C.A., 2010a. Asbestos, carbon nanotubes and the pleural mesothelium: a review of the hypothesis regarding the role of long fibre retention in the parietal pleura, inflammation and mesothelioma. Part Fibre Toxicol 7, 5.

Donaldson, K., Poland, C.A., 2012. Inhaled nanoparticles and lung cancer - what we can learn from conventional particle toxicology. Swiss Med Wkly 142, w13547.

Donaldson, K., Poland, C.A., Murphy, F.A., MacFarlane, M., Chernova, T., Schinwald, A., 2013. Pulmonary toxicity of carbon nanotubes and asbestos - similarities and differences. Adv Drug Deliv Rev 65, 2078-86.

Donaldson, K., Poland, C.A., Schins, R.P., 2010b. Possible genotoxic mechanisms of nanoparticles: criteria for improved test strategies. Nanotoxicology 4, 414-20.

Elder, A., Oberdorster, G., 2006. Translocation and effects of ultrafine particles outside of the lung. Clin Occup Environ Med 5, 785-96.

Ghio, A.J., Sobus, J.R., Pleil, J.D., Madden, M.C., 2012. Controlled human exposures to diesel exhaust. Swiss Med Wkly 142, w13597.

Goldberg, M.S., Labreche, F., Weichenthal, S., Lavigne, E., Valois, M.F., Hatzopoulou, M., Van Ryswyk, K., Shekarrizfard, M., Villeneuve, P.J., Crouse, D., Parent, M.E., 2017. The association between the incidence of postmenopausal breast cancer and concentrations at street-level of nitrogen dioxide and ultrafine particles. Environ Res 158, 7-15.

Guida, F., Paget-Bailly, S., Lamkarkach, F., Gaye, O., Ducamp, S., Menvielle, G., Papadopoulos, A., Matrat, M., Fevotte, J., Cenee, S., Cyr, D., Schmaus, A., Carton, M., Radoi, L., LapotreLedoux, B., Molinie, F., Luce, D., Stucker, I., 2013. Risk of lung cancer associated with occupational exposure to mineral wools: updating knowledge from a french population-based case-control study, the ICARE study. J Occup Environ Med 55, 786-95.

Heusinkveld, H.J., Wahle, T., Campbell, A., Westerink, R.H.S., Tran, L., Johnston, H., Stone, V., Cassee, F.R., Schins, R.P.F., 2016. Neurodegenerative and neurological disorders by small inhaled particles. Neurotoxicology 56, 94-106.

Hopkins, L.E., Laing, E.A., Peake, J.L., Uyeminami, D., Mack, S.M., Li, X., Smiley-Jewell, S., Pinkerton, K.E., 2018. Repeated Iron-Soot Exposure and Nose-to-brain Transport of Inhaled Ultrafine Particles. Toxicol Pathol 46, 75-84.

Ju, L., Wu, W., Yu, M., Lou, J., Wu, H., Yin, X., Jia, Z., Xiao, Y., Zhu, L., Yang, J., 2017. Different Cellular Response of Human Mesothelial Cell MeT-5A to Short-Term and Long-Term Multiwalled Carbon Nanotubes Exposure. Biomed Res Int.

Lacourt, A., Leveque, E., Guichard, E., Gilg Soit Ilg, A., Sylvestre, M.P., Leffondre, K., 2017. Dosetime-response association between occupational asbestos exposure and pleural mesothelioma. Occup Environ Med 74, 691-697.

Leffondre, K., Abrahamowicz, M., Xiao, Y., Siemiatycki, J., 2006. Modelling smoking history using a comprehensive smoking index: application to lung cancer. Stat Med 25, 4132-46. 
Liou, S.H., Tsai, C.S., Pelclova, D., Schubauer-Berigan, M.K., Schulte, P.A., 2015. Assessing the first wave of epidemiological studies of nanomaterial workers. J Nanopart Res 17, 413.

Loomis, D., Huang, W., Chen, G., 2014. The International Agency for Research on Cancer (IARC) evaluation of the carcinogenicity of outdoor air pollution: focus on China. Chin J Cancer 33, 189-96.

Luce, D., Stucker, I., Group, I.S., 2011. Investigation of occupational and environmental causes of respiratory cancers (ICARE): a multicenter, population-based case-control study in France. BMC Public Health 11, 928.

Magaye, R., Zhao, J., Bowman, L., Ding, M., 2012. Genotoxicity and carcinogenicity of cobalt-, nickel- and copper-based nanoparticles. Exp Ther Med 4, 551-561.

Magdolenova, Z., Collins, A., Kumar, A., Dhawan, A., Stone, V., Dusinska, M., 2014. Mechanisms of genotoxicity. A review of in vitro and in vivo studies with engineered nanoparticles. Nanotoxicology 8, 233-78.

McCreanor, J., Cullinan, P., Nieuwenhuijsen, M.J., Stewart-Evans, J., Malliarou, E., Jarup, L., Harrington, R., Svartengren, M., Han, I.K., Ohman-Strickland, P., Chung, K.F., Zhang, J., 2007. Respiratory effects of exposure to diesel traffic in persons with asthma. N Engl J Med $357,2348-58$.

McNeill, K.A., 2016. Epidemiology of Brain Tumors. Neurol Clin 34, 981-998.

Messing, K., Dumais, L., Courville, J., Seifert, A.M., Boucher, M., 1994. Evaluation of exposure data from men and women with the same job title. J Occup Med 36, 913-7.

Moller, P., Danielsen, P.H., Karottki, D.G., Jantzen, K., Roursgaard, M., Klingberg, H., Jensen, D.M., Christophersen, D.V., Hemmingsen, J.G., Cao, Y., Loft, S., 2014. Oxidative stress and inflammation generated DNA damage by exposure to air pollution particles. Mutat Res Rev Mutat Res 762, 133-66.

Nakane, H., 2012. Translocation of particles deposited in the respiratory system: a systematic review and statistical analysis. Environ Health Prev Med 17, 263-74.

Nemmar, A., Vanbilloen, H., Hoylaerts, M.F., Hoet, P.H., Verbruggen, A., Nemery, B., 2001. Passage of intratracheally instilled ultrafine particles from the lung into the systemic circulation in hamster. Am J Respir Crit Care Med 164, 1665-8.

Oberdorster, G., Elder, A., Rinderknecht, A., 2009. Nanoparticles and the brain: cause for concern? J Nanosci Nanotechnol 9, 4996-5007.

Oberdorster, G., Oberdorster, E., Oberdorster, J., 2005. Nanotoxicology: an emerging discipline evolving from studies of ultrafine particles. Environ Health Perspect 113, 823-39.

Oberdorster, G., Sharp, Z., Atudorei, V., Elder, A., Gelein, R., Lunts, A., Kreyling, W., Cox, C., 2002. Extrapulmonary translocation of ultrafine carbon particles following whole-body inhalation exposure of rats. J Toxicol Environ Health A 65, 1531-43.

Ohlwein, S., Kappeler, R., Kutlar Joss, M., Kunzli, N., Hoffmann, B., 2019. Health effects of ultrafine particles: a systematic literature review update of epidemiological evidence. Int J Public Health 64, 547-559.

Ostro, B., Hu, J., Goldberg, D., Reynolds, P., Hertz, A., Bernstein, L., Kleeman, M.J., 2015. Associations of mortality with long-term exposures to fine and ultrafine particles, species and 
sources: results from the California Teachers Study Cohort. Environ Health Perspect 123, $549-56$.

Patel, M., Pilcher, J., Pritchard, A., Perrin, K., Travers, J., Shaw, D., Holt, S., Harwood, M., Black, P., Weatherall, M., Beasley, R., Group, S.S., 2013. Efficacy and safety of maintenance and reliever combination budesonide-formoterol inhaler in patients with asthma at risk of severe exacerbations: a randomised controlled trial. Lancet Respir Med 1, 32-42.

Rolland, P., Gramond, C., Lacourt, A., Astoul, P., Chamming's, S., Ducamp, S., Frenay, C., GalateauSalle, F., Ilg, A.G., Imbernon, E., Le Stang, N., Pairon, J.C., Goldberg, M., Brochard, P., Group, P.S., 2010. Occupations and industries in France at high risk for pleural mesothelioma: A population-based case-control study (1998-2002). Am J Ind Med 53, 1207-19.

Schlaefer, K., Schlehofer, B., Schuz, J., 2009. Validity of self-reported occupational noise exposure. Eur J Epidemiol 24, 469-75.

Schulte, P.A., Leso, V., Niang, M., Iavicoli, I., 2019. Current state of knowledge on the health effects of engineered nanomaterials in workers: a systematic review of human studies and epidemiological investigations. Scand J Work Environ Health 45, 217-238.

Sinharay, R., Gong, J., Barratt, B., Ohman-Strickland, P., Ernst, S., Kelly, F.J., Zhang, J.J., Collins, P., Cullinan, P., Chung, K.F., 2018. Respiratory and cardiovascular responses to walking down a traffic-polluted road compared with walking in a traffic-free area in participants aged 60 years and older with chronic lung or heart disease and age-matched healthy controls: a randomised, crossover study. Lancet 391, 339-349.

Stone, V., Miller, M.R., Clift, M.J.D., Elder, A., Mills, N.L., Moller, P., Schins, R.P.F., Vogel, U., Kreyling, W.G., Alstrup Jensen, K., Kuhlbusch, T.A.J., Schwarze, P.E., Hoet, P., Pietroiusti, A., De Vizcaya-Ruiz, A., Baeza-Squiban, A., Teixeira, J.P., Tran, C.L., Cassee, F.R., 2017. Nanomaterials Versus Ambient Ultrafine Particles: An Opportunity to Exchange Toxicology Knowledge. Environ Health Perspect 125, 106002.

Suzui, M., Futakuchi, M., Fukamachi, K., Numano, T., Abdelgied, M., Takahashi, S., Ohnishi, M., Omori, T., Tsuruoka, S., Hirose, A., Kanno, J., Sakamoto, Y., Alexander, D.B., Alexander, W.T., Jiegou, X., Tsuda, H., 2016. Multiwalled carbon nanotubes intratracheally instilled into the rat lung induce development of pleural malignant mesothelioma and lung tumors. Cancer Sci 107, 924-35.

Teschke, K., Olshan, A.F., Daniels, J.L., De Roos, A.J., Parks, C.G., Schulz, M., Vaughan, T.L., 2002. Occupational exposure assessment in case-control studies: opportunities for improvement. Occup Environ Med 59, 575-93; discussion 594.

Toyokuni, S., 2013. Genotoxicity and carcinogenicity risk of carbon nanotubes. Adv Drug Deliv Rev 65, 2098-110.

Val, S., Hussain, S., Boland, S., Hamel, R., Baeza-Squiban, A., Marano, F., 2009. Carbon black and titanium dioxide nanoparticles induce pro-inflammatory responses in bronchial epithelial cells: need for multiparametric evaluation due to adsorption artifacts. Inhal Toxicol 21 Suppl 1, $115-22$.

Weichenthal, S., 2012. Selected physiological effects of ultrafine particles in acute cardiovascular morbidity. Environ Res 115, 26-36.

Weichenthal, S., Bai, L., Hatzopoulou, M., Van Ryswyk, K., Kwong, J.C., Jerrett, M., van Donkelaar, A., Martin, R.V., Burnett, R.T., Lu, H., Chen, H., 2017a. Long-term exposure to ambient 
ultrafine particles and respiratory disease incidence in in Toronto, Canada: a cohort study. Environ Health 16, 64.

Weichenthal, S., Lavigne, E., Valois, M.F., Hatzopoulou, M., Van Ryswyk, K., Shekarrizfard, M., Villeneuve, P.J., Goldberg, M.S., Parent, M.E., 2017b. Spatial variations in ambient ultrafine particle concentrations and the risk of incident prostate cancer: A case-control study. Environ Res 156, 374-380.

Weichenthal, S., Olaniyan, T., Christidis, T., Lavigne, E., Hatzopoulou, M., Van Ryswyk, K., Tjepkema, M., Burnett, R., 2020. Within-city Spatial Variations in Ambient Ultrafine Particle Concentrations and Incident Brain Tumors in Adults. Epidemiology 31, 177-183.

Wichmann, H.E., Spix, C., Tuch, T., Wolke, G., Peters, A., Heinrich, J., Kreyling, W.G., Heyder, J., 2000. Daily mortality and fine and ultrafine particles in Erfurt, Germany part I: role of particle number and particle mass. Res Rep Health Eff Inst 5-86; discussion 87-94.

Xu, H., Ho, S.S., Cao, J., Guinot, B., Kan, H., Shen, Z., Ho, K.F., Liu, S., Zhao, Z., Li, J., Zhang, N., Zhu, C., Zhang, Q., Huang, R., 2017. A 10-year observation of PM2.5-bound nickel in Xi' an, China: Effects of source control on its trend and associated health risks. Sci Rep 7, 41132. 
Table 1: Exposure parameters assessed in the MatPuf job-exposure matrix according the level of assessment

\begin{tabular}{lll}
\hline Assessment level $\quad$ Probability of exposure & Frequency of exposure & Intensity \\
exposure
\end{tabular}

$\%$ of exposed workers through the

Occupational code* implementation of the work process $^{\dagger} j$

$\times$ work process among workers involved the occupational code $i$

\begin{tabular}{ll} 
Categorization & $\begin{array}{c}\text { Numerical } \\
\text { value }\end{array}$ \\
\hline Possible: $>0-10 \%$ & 0.05 \\
Probable: $>10-50 \%$ & 0.30 \\
Highly probable: $>50 \%$ & 0.75
\end{tabular}

$\%$ of exposed workers among workers

Occupational code involved in the occupation $i$
$\%$ of working time during which the exposure

occurred through the implementation of the work process $j$ in occupational code $i$ on a $8 \mathrm{~h}$ typical working day and on a typical working Not assessed due to heterogeneity of year

\begin{tabular}{ll} 
Categorization & $\begin{array}{l}\text { Numerical } \\
\text { value }\end{array}$ \\
\hline Sporadic: $>0-5 \%$ & 0.025 \\
Occasional: $>5-30 \%$ & 0.175 \\
Frequent: $>30-70 \%$ & 0.50 \\
Permanent: $>70 \%$ & 0.85
\end{tabular}

$\%$ of working time during which the exposure occurred in occupation I on a $8 \mathrm{~h}$ typical 
working day and on a typical working year

$$
1-\prod_{i=1}^{\mathrm{n}}\left(1 \text {-Probability }{ }_{\text {occupational code } i \times \text { work process } j}\right) \quad 1-\prod_{i=1}^{\mathrm{n}}\left[\begin{array}{c}
1-\left(\text { Probability }_{\text {occupational code } i \times \text { work process } j} \times\right. \\
\text { Frequency } \left._{\text {occupational code } i \times \text { work process } j}\right)
\end{array}\right]
$$

n: number of work processes assessed for the

occupation $i$

n: number of work processes assessed for the occupation $i$

\section{* Occupational code defining according to the International Standard Classification of Occupations, Revised Edition 1968}

$\dagger$ From a list of 57 pre-defined work processes assessed as unintentionally-emitting nanoscale particles 


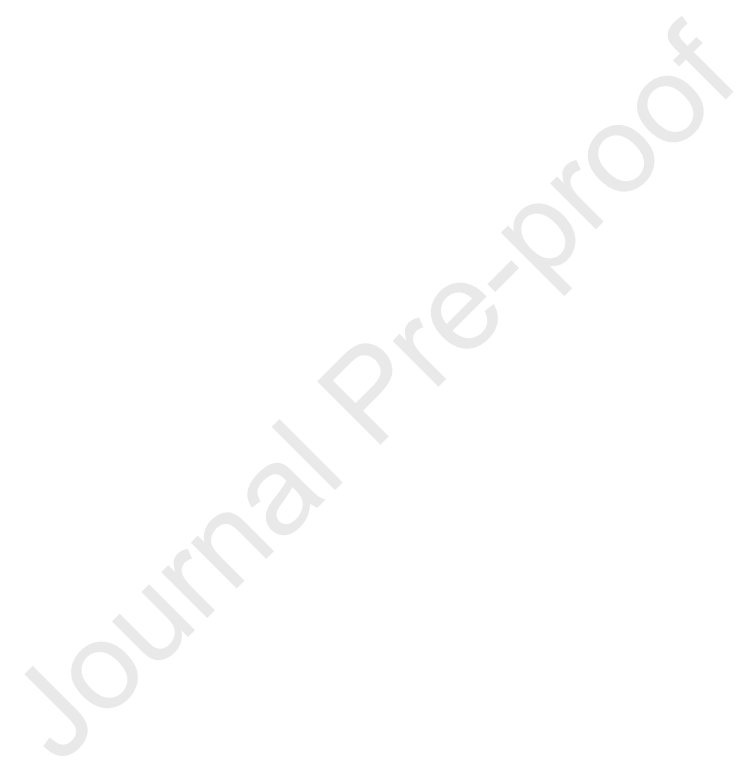


Table 2 : Most represented occupations exposed to nanoscale particles with a probability of exposure greater than 50\% among men, French case-control studies on lung cancer (ICARE study, 2001-2007), pleural mesothelioma ((PNSM study, 1998-2002) and central nervous system tumors (CERENAT study, 2004-2006).

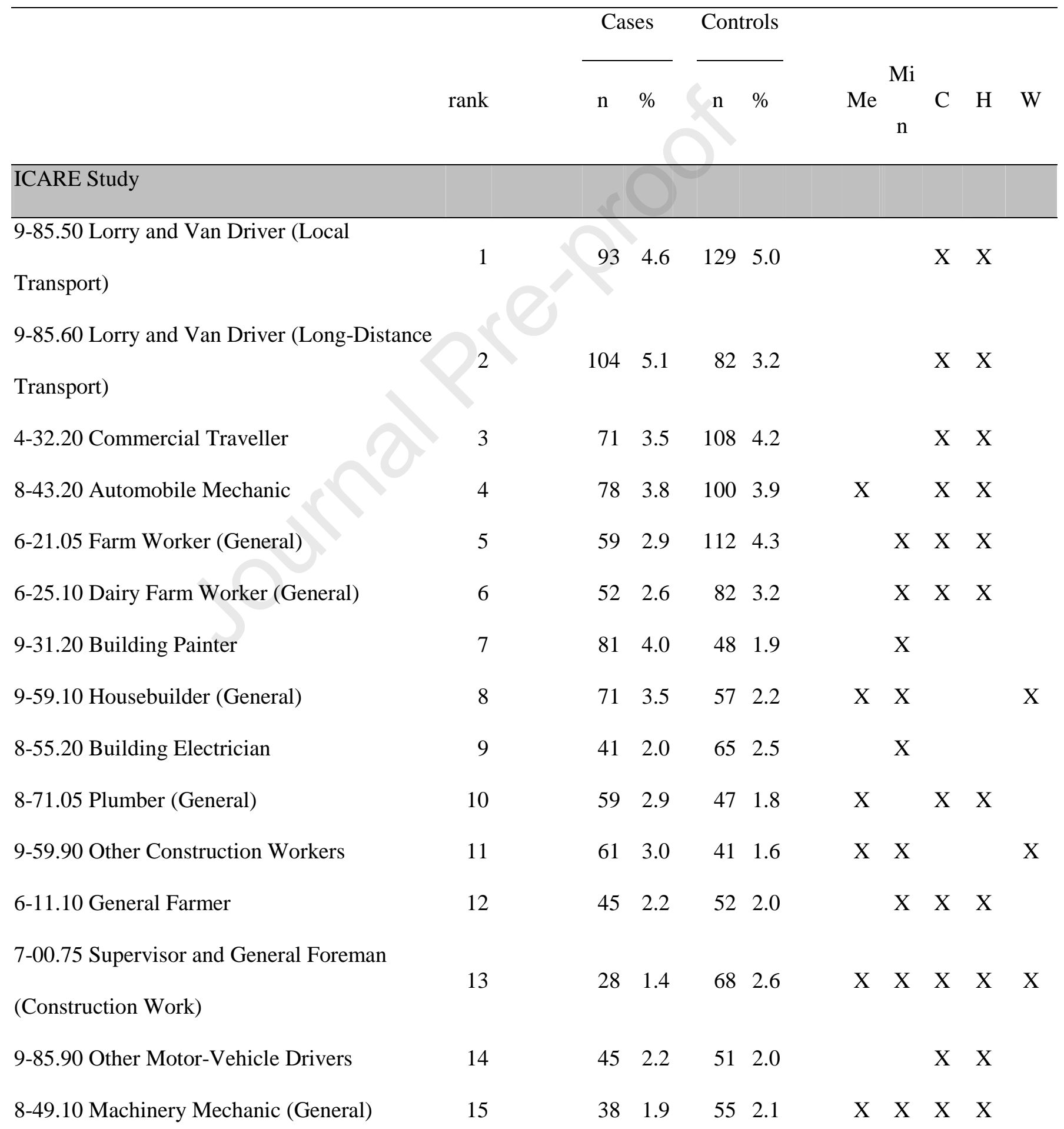


6-21.10 Farm Helper (General)

4-31.20 Technical Salesman

9-99.10 Labourer

5-31.30 Cook, except Private Service

8-73.10 Sheet-Metal Worker, General
16

17

18

19

20 $\begin{array}{llll}36 & 1.8 & 57 & 2.2\end{array}$

$\begin{array}{llll}41 & 2.0 & 48 & 1.9\end{array}$

$\begin{array}{llll}52 & 2.6 & 37 & 1.4\end{array}$

$41 \quad 2.0$

$45 \quad 1.7$

$43 \quad 2.1$

$37 \quad 1.4$
$\mathrm{X} \quad \mathrm{X}$

X X

X $\quad X \quad X$

X X

$\mathrm{X} \quad \mathrm{X}$

X

\section{PNSM study \\ 9-85.50 Lorry and Van Driver (Local}

Transport)

6-21.05 Farm Worker (General)

8-73.10 Sheet-Metal Worker, General

4-32.20 Commercial Traveller

6-11.10 General Farmer

8-43.20 Automobile Mechanic

6

9-99.10 Labourer

7

6-21.10 Farm Helper (General)

9-51.20 Bricklayer (Construction)

9

$\begin{array}{llll}13 & 3.5 & 40 & 5.5\end{array}$

X X

1

.

$\begin{array}{llll}11 & 3.0 & 36 & 4.9\end{array}$

$\begin{array}{llll}30 & 8.1 & 15 & 2.1\end{array}$

$\begin{array}{llll}9 & 2.4 & 30 & 4.1\end{array}$

$\begin{array}{llll}2 & 0.5 & 37 & 5.1\end{array}$

$\begin{array}{llll}13 & 3.5 & 22 & 3.0\end{array}$

$\begin{array}{llll}15 & 4.0 & 13 & 1.8\end{array}$

$\begin{array}{llll}4 & 1.1 & 24 & 3.3\end{array}$

$\begin{array}{llll}10 & 2.7 & 17 & 2.3\end{array}$

7-00.50 Supervisor and General Foreman

(Manufacturing of Machinery and Metal

Product

7-00.75 Supervisor and General Foreman

(Construction Work)

8-49.10 Machinery Mechanic (General)

8-71.05 Plumber (General)

8-71.10 Pipe Fitter (General)

8-49.70 Plant Maintenance Mechanic

$\begin{array}{llll}12 & 3.2 & 11 & 1.5\end{array}$

$15 \quad 4.0$

$7 \quad 1.0$

$20 \quad 5.4$

10.1

$13 \quad 3.5$

81.1

$8 \quad 2.2$

131.8
$\begin{array}{llll}X & X & X\end{array}$

$\mathrm{X} \quad \mathrm{X} \quad \mathrm{X}$

X $\quad X \quad X$

$\begin{array}{lllll}X & X & X & X & X\end{array}$

X $\quad X \quad X$ 


\begin{tabular}{|c|c|c|c|c|c|c|c|}
\hline 8-72.10 Gas and Electronic Welder (General) & 17 & 12 & 3.2 & 7 & 1.0 & $\mathrm{X}$ & $X$ \\
\hline 4-31.20 Technical Salesman & 18 & 6 & 1.6 & 13 & 1.8 & & $X$ \\
\hline 9-54.20 Construction Joiner & 19 & 9 & 2.4 & 9 & 1.2 & & \\
\hline 7-76.20 Bread Baker & 20 & 5 & 1.3 & 13 & 1.8 & & $\mathrm{X}$ \\
\hline
\end{tabular}

CERENAT study
6-21.05 Farm Worker (General)
6-11.10 General Farmer
9-85.50 Lorry and Van Driver (Local
Transport)

$\begin{array}{lllllllll}1 & 17 & 6.6 & 26 & 5.1 & & X & X & X\end{array}$

2

$12 \quad 4.7 \curlyvee 21 \quad 4.1$

$\begin{array}{lll}X & X & X\end{array}$

3

$\begin{array}{llll}9 & 3.5 & 18 & 3.5\end{array}$

X $\mathrm{X}$

6-12.30 Orchard, Vineyard and Related Tree and Shrub Crop Farmer

$\begin{array}{llllllll}4 & 10 & 3.9 & 16 & 3.1 & & X & X\end{array}$

8-43.20 Automobile Mechanic

$\begin{array}{llllllllll}5 & 10 & 3.9 & 15 & 2.9 & & \text { X } & \text { X } & \text { X }\end{array}$

4-32.20 Commercial Traveller

6

$\begin{array}{llll}8 & 3.1 & 17 & 3.3\end{array}$

$\mathrm{X} \quad \mathrm{X}$

8-71.05 Plumber (General)

$\begin{array}{llll}8 & 3.1 & 16 & 3.1\end{array}$

$X \quad X \quad X$

6-23.30 Vineyard Worker

$\begin{array}{llll}7 & 2.7 & 9 & 1.8\end{array}$

$\mathrm{X} \quad \mathrm{X}$

9-31.20 Building Painter

$\begin{array}{llll}9 & 3.5 & 6 & 1.2\end{array}$

$\mathrm{X}$

9-51.90 Other Bricklayers, Stonemasons and

Tile Setters

10

$\begin{array}{llll}6 & 2.3 & 9 & 1.8\end{array}$

$\mathrm{X}$

9-54.10 Carpenter, General

$\begin{array}{llll}4 & 1.6 & 11 & 2.2\end{array}$

$\mathrm{X}$

7-76.20 Bread Baker

$\begin{array}{llll}9 & 3.5 & 5 & 1.0\end{array}$

X X

8-72.20 Electric Arc Welder (Hand)

$\begin{array}{llll}7 & 2.7 & 7 & 1.4\end{array}$

$\mathrm{X}$

4-31.20 Technical Salesman

14

$\begin{array}{llll}4 & 1.6 & 10 & 2.0\end{array}$

X $\mathrm{X}$

7-00.75 Supervisor and General Foreman

(Construction Work)

8-55.20 Building Electrician

16

$\begin{array}{llll}5 & 1.9 & 7 & 1.4\end{array}$

$\mathrm{X}$

0-34.90 Other Electrical and Electronics

17

$\begin{array}{llll}2 & 0.8 & 10 & 2.0\end{array}$

X 
Engineering Technicians

6-25.10 Dairy Farm Worker (General)

8-49.10 Machinery Mechanic (General)

4-52.30 Canvasser
18

19

20 $\begin{array}{llll}6 & 2.3 & 5 & 1.0\end{array}$

$\begin{array}{llll}5 & 1.9 & 6 & 1.2\end{array}$

$\begin{array}{ll}6 & 2.3\end{array}$

$\begin{array}{ll}4 & 0.8\end{array}$

Me : Metallic particles; Min : mineral particles; $\mathrm{C}$ : Carbon particles ; $\mathrm{H}:$ polycyclic aromatic hydrocarbon particles; $\mathrm{W}$ : wood particles 
Table 3: Association between occupational exposure to nanoscale particles and respiratory cancers (lung cancer and pleural mesothelioma) among men, French case-control studies on lung cancer (ICARE study, 2001-2007) and pleural mesothelioma (PNSM study, 1998-2002).

\begin{tabular}{|c|c|c|c|c|c|c|c|c|c|c|c|c|}
\hline & \multicolumn{6}{|c|}{ ICARE Study (Lung cancer study) } & \multicolumn{6}{|c|}{ PNSM study (Pleural mesothelioma study) } \\
\hline & \multicolumn{2}{|c|}{$\begin{array}{c}\text { Cases } \\
(\mathrm{N}=2,029)\end{array}$} & \multicolumn{2}{|c|}{$\begin{array}{l}\text { Controls } \\
(\mathrm{N}=2,591)\end{array}$} & \multirow[b]{2}{*}{$\mathrm{OR}^{*}$} & \multirow[b]{2}{*}{$95 \% \mathrm{CI}$} & \multicolumn{2}{|c|}{$\begin{array}{c}\text { Cases } \\
(\mathrm{N}=371)\end{array}$} & \multicolumn{2}{|c|}{$\begin{array}{l}\text { Controls } \\
(\mathrm{N}=730)\end{array}$} & \multirow[b]{2}{*}{$\mathrm{OR}^{\dagger}$} & \multirow[b]{2}{*}{$95 \% \mathrm{CI}$} \\
\hline & $\mathrm{n}$ & $\%$ & $\mathrm{n}$ & $\%$ & & & $\mathrm{n}$ & $\%$ & $\mathrm{n}$ & $\%$ & & \\
\hline Not exposed & 263 & 13.0 & 582 & 22.5 & 1.00 & & 35 & 9.4 & 171 & 23.4 & 1.00 & \\
\hline Uncertain $^{\ddagger}$ & 154 & & 210 & & 1.50 & $1.09-2.06$ & 22 & 5.9 & 87 & 11.9 & 0.62 & $0.32-1.23$ \\
\hline Exposed $^{\S}$ & 1612 & 76.4 & 1799 & 69.4 & 1.51 & $1.22-1.86$ & 314 & 84.7 & 472 & 64.7 & 0.78 & $0.46-1.33$ \\
\hline \multicolumn{13}{|c|}{ Highest probability of exposure (\%) } \\
\hline$>50-90$ & 487 & 24.0 & 526 & 20.3 & 1.59 & $1.25-2.02$ & 62 & 16.7 & 144 & 22.4 & 0.75 & $0.42-1.36$ \\
\hline$>90$ & 1125 & 55.4 & 1273 & 49.1 & 1.46 & $1.17-1.83$ & 252 & 67.9 & 328 & 51.0 & 0.80 & $0.46-1.39$ \\
\hline Duration of exposure (years) ${ }^{\S}$ & & & & & 1.06 & $0.99-1.13$ & & & & & 1.01 & $0.99-1.02$ \\
\hline Mean (SD) & \multicolumn{2}{|c|}{$27.2(14.3)$} & \multicolumn{2}{|c|}{$25.2(14.3)$} & & & \multicolumn{2}{|c|}{$28.1(11.8)$} & \multicolumn{2}{|c|}{$25.9(14.2)$} & & \\
\hline Min-Max & \multicolumn{2}{|c|}{$0.5-56$} & \multicolumn{2}{|c|}{$0.25-56$} & & & \multicolumn{2}{|c|}{$1-56$} & \multicolumn{2}{|c|}{$1-53$} & & \\
\hline
\end{tabular}


Total weighted duration of exposure (years) ${ }^{\mathrm{II}}$

$$
\text { Mean (SD) }
$$

Min-Max
1.09

$0.99-1.20$

$10.8(9.0)$

$0.1-47.5$

$0.0-44.1$
$1.03 \quad 1.01-1.05$

$15.9(11.1) \quad 11.1(9.3)$

$0.2-48.2 \quad 0.0-43.8$

* Odds ratio estimated from unconditional logistic regression adjusted for age (using fractional polynomial of degree 2 with powers $\mathrm{p}=-2$ and $\mathrm{q}=-2$ ), district of residence, smoking comprehensive index, the cumulative index of exposure to asbestos (using fractional polynomial of degree 1 with powers $\mathrm{p}=-1$ ) and the cumulative index of exposure to silica (using fractional polynomial of degree 1 with powers $\mathrm{p}=-1$ ).

${ }^{\dagger}$ Odds ratio estimated from conditional logistic regression stratified by age (5-years categories), district of residence and further adjusted for age as a continuous variable and the cumulative index of exposure to asbestos (using fractional polynomial of degree 2 with powers $\mathrm{p}=-2$ and $\mathrm{q}=0.5$ ).

Highest probability of exposure $\leq 50 \%$ but greater than $0 \%$.

${ }^{\S}$ Highest probability of exposure $>50 \%$.

"Analyses restricted to ever exposed only. 
Table 4: Association between occupational exposure to nanoscale particles and central nervous system tumors among men (CERENAT study, 2004-2006).

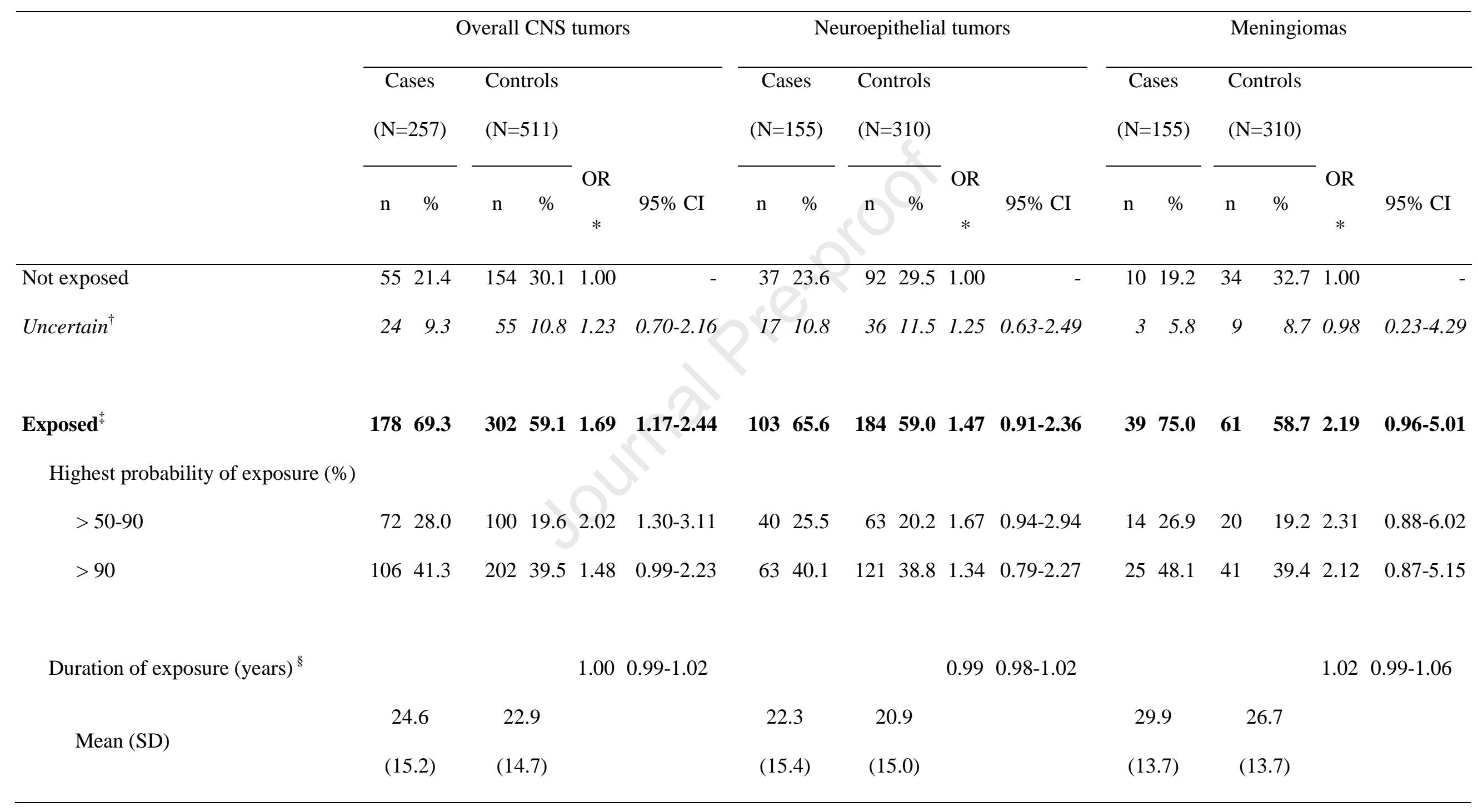




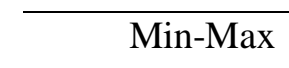

$1-65$

$1-55$

$1-56$

$1-55$

$2-65$

$2-54$

Total weighted duration of exposure

(years) $)^{\S}$

$0.98 \quad 0.96-1.01$

$0.98 \quad 0.95-1.02$

$0.99 \quad 0.95-1.04$

$\begin{array}{lcccccc}\text { Mean (SD) } & 8.8(7.4) & 9.8(9.4) & 8.5(7.1) & 9.1(9.5) & 10.9(9.5) \\ \text { Min-Max } & 0.1-38.1 & 0.1-46.5 & 0.1-29.1 & 0.1-46.5 & 0.2-37.4\end{array}$

* Odds ratio estimated from conditional logistic regression models stratified by age (5-years categories), district of residence and further adjusted for age as a continuous variable.

${ }^{\dagger}$ Highest probability of exposure $\leq 50 \%$ but greater than $0 \%$.

${ }^{\ddagger}$ Highest probability of exposure $>50 \%$.

${ }^{\S}$ Analyses restricted to ever exposed only. 
Table 5: Association between occupational exposure to main chemical families of nanoscale particles and respiratory cancers (lung cancer and pleural mesothelioma) among men, French case-control studies on lung cancer (ICARE study, 2001-2007) and on pleural mesothelioma (PNSM study, 19982002).

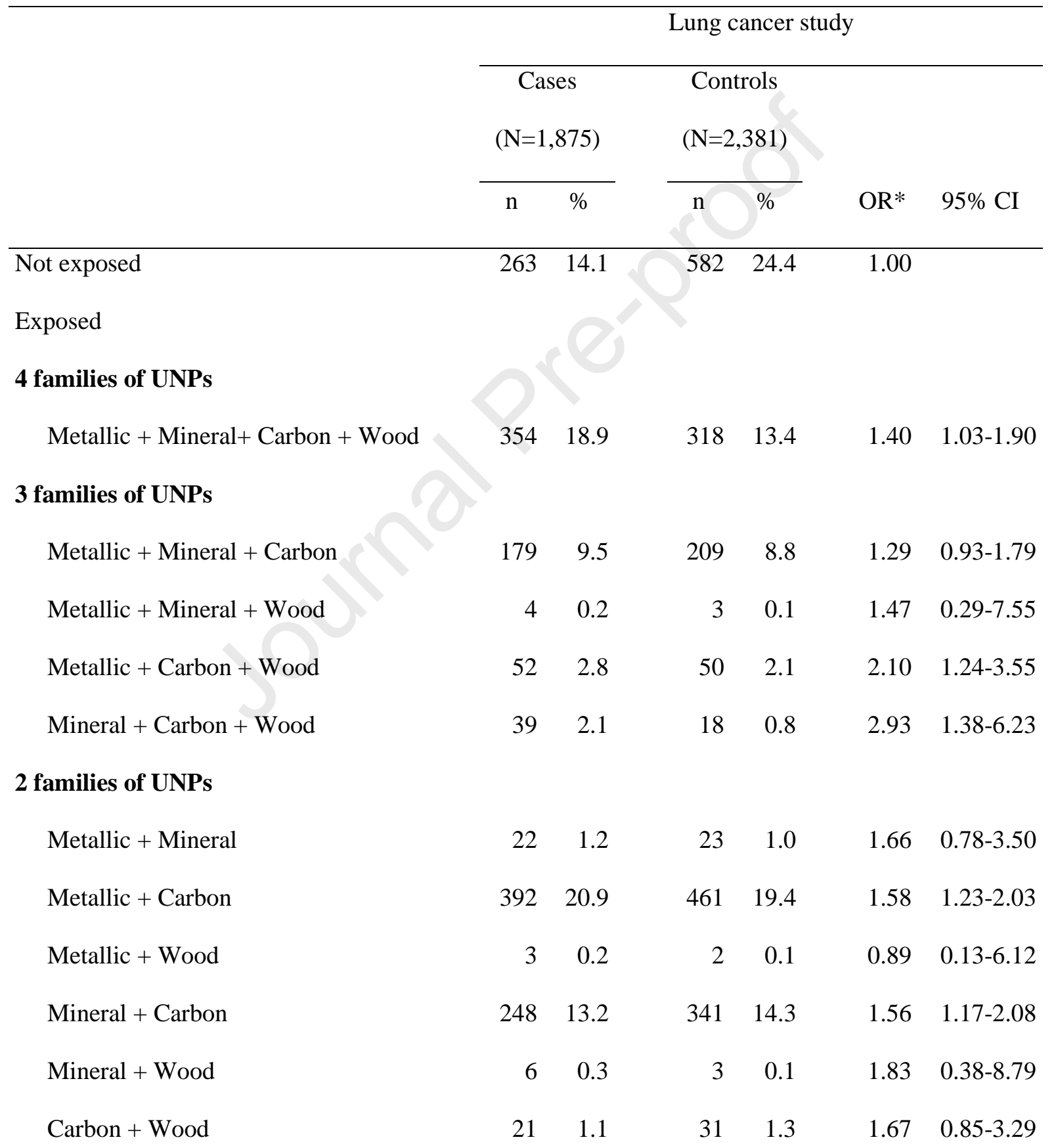

1 family of UNPs only 


\begin{tabular}{lrrrrrr}
\hline Metallic only & 10 & 0.5 & 12 & 0.5 & 2.19 & $0.77-6.23$ \\
Mineral only & 29 & 1.5 & 15 & 0.6 & 1.26 & $0.57-2.82$ \\
Carbon only & 231 & 12.3 & 272 & 11.4 & 1.41 & $1.06-1.87$ \\
Wood only & 22 & 1.2 & 41 & 1.7 & 1.44 & $0.74-2.81$ \\
\hline
\end{tabular}

* Odds ratio estimated from unconditional logistic regression adjusted for age (using fractional polynomial of degree 2 with powers $\mathrm{p}=-2$ and $\mathrm{q}=-2$ ), district of residence, smoking comprehensive index, the cumulative index of exposure to asbestos (using fractional polynomial of degree 1 with powers $\mathrm{p}=-1$ ) and the cumulative index of exposure to silica (using fractional polynomial of degree 1 with powers $\mathrm{p}=-1)$. 


\section{Highlights}

- nanoscale particles may have a carcinogenic effect on humans

- Positive association between lung cancer, brain tumors and nanoscale particles

- Retrospective exposure assessment of nanoscale particles by a job-exposure matrix 


\section{Declaration of interests}

$\bigotimes$ The authors declare that they have no known competing financial interests or personal relationships that could have appeared to influence the work reported in this paper.

$\square$ The authors declare the following financial interests/personal relationships which may be considered as potential competing interests: 